$10-2010$

\title{
Compensation of Torque Ripple in High Performance BLDC Motor Drives
}

Ilhwan Kim

Kangwon National University, ihkim@kangwon.ac.kr

Nobuaki Nakazawa

Eol/hinthathisianersitydditional works at: https://engagedscholarship.csuohio.edu/enece_facpub

Part of the Controls and Control Theory Commons

sungsoo Kim

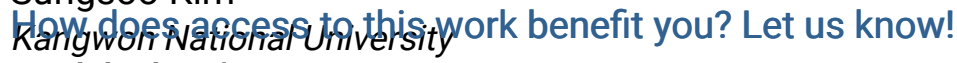

Publisher's Statement


Kangwon National University

papersonline.net. Changes resulting from the publishing process, such as peer review, editing,

Charestlofus, structural formatting, and other quality control mechanisms may not be reflected in

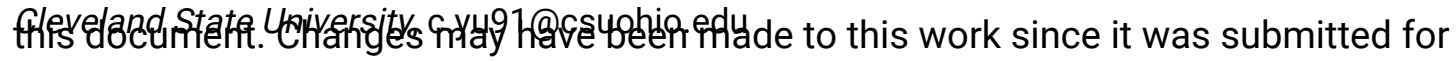
publication. A definitive version was subsequently published in ifac-papersonline.net, DOI 10.1016/j.conengprac.2010.06.003

\section{Original Citation}

Kim, I., Nakazawa, N., Kim, S., Park, C., , \& Yu, C. (2010). Compensation of torque ripple in high performance BLDC motor drives. Control Engineering Practice, 18(10), 1166-1172. doi:10.1016/ j.conengprac. 2010.06 .003

\section{Repository Citation}

Kim, Ilhwan; Nakazawa, Nobuaki; Kim, Sungsoo; Park, Chanwon; and Yu, Chansu, "Compensation of Torque Ripple in High Performance BLDC Motor Drives" (2010). Electrical Engineering \& Computer Science Faculty Publications. 69.

https://engagedscholarship.csuohio.edu/enece_facpub/69

This Article is brought to you for free and open access by the Electrical Engineering \& Computer Science Department at EngagedScholarship@CSU. It has been accepted for inclusion in Electrical Engineering \& Computer Science Faculty Publications by an authorized administrator of EngagedScholarship@CSU. For more information, please contact library.es@csuohio.edu. 


\title{
Compensation of torque ripple in high performance BLDC motor drives
}

\author{
Ilhwan Kim ${ }^{\mathrm{a}, *}$, Nobuaki Nakazawa ${ }^{\mathrm{b}}$, Sungsoo Kim ${ }^{\mathrm{c}}$, Chanwon Park ${ }^{\mathrm{a}}$, Chansu Yu ${ }^{\mathrm{d}}$ \\ ${ }^{a}$ Department of Electrical \& Electronic Engineering, Kangwon National University, Republic of Korea \\ ${ }^{\mathrm{b}}$ Department of Production Science and Technology, Gunma University. Japan \\ 'Department of Industrial Engineering. Kangwon National University, Republic of Korea \\ ${ }^{\mathrm{D}}$ Department of Electrical and Computer Engineering, Cleveland State University, Ohio, USA
}

\section{Introduction}

Permanent magnet $A C$ synchronous motors are used with preference for applications in high performance positioning systems and machine tool spindle drives because of their attractive characteristics in such categories as power density, torque-to-inertia ratio, and electrical efficiency. There are two classes of PMAC motor drives which can be characterized by the shapes of their respective back-EMF waveforms; sinusoidal and trapezoidal. Under idealized conditions, each of these two types of PMAC drives is capable of delivering perfectly smooth instantaneous torque waveforms. In sinusoidal PMAC motor drives, both the motor back-EMF and the current excitation waveforms are perfectly sinusoidal for ideally smooth torque generation. Sinusoidal back-EMF waveforms require a sinusoidal flux density distribution around the airgap. Sinusoidal phase currents are typically developed using a current-regulated inverter that requires individual phase current sensors and a high-resolution rotor position sensor to maintain accurate synchronization of the excitation waveforms with the rotor angular position at every time instant. Any source of non-ideal properties which causes either the phase currents or the back-EMF waveforms to diverge from their purely sinusoidal shapes will typically give rise to undesired pulsating torque components. In general the inverter contributes to the torque ripple owing to time harmonics in the current waveforms, and to time-varying delays between the commanded and the actual currents.

\footnotetext{
- Corresponding author.

E-mail address: ihkim@kangwon.ac.kr (1. Kim).
}

Trapezoidal PMAC motor drives, also known as brushless DC drives, exhibit some notable distinctions from their sinusoidal counterparts. Excitation waveforms for BLDC motors take the form of square-wave current waveforms. The nature of the excitation waveforms permits some important system simplifications compared to sinusoidal PMAC machines. In particular, the resolution requirements for the rotor position sensor are much lower with BLDC motors since only six commutation instants per electrical cycle must be sensed. In addition, the BLDC motor drive only requires a single current sensor in the inverter DC link. In fact, it is the simplicity of the BLDC motor drive that is responsible for causing an additional source of ripple torque commonly known as commutation torque to develop (Carlson, LajoieMazenc, \& Fagundes, 1992: Safi, Acarnley, \& Jack, 1995). The commutation torque, as sketched in Fig. 1, takes the form of torque spikes or dips which are generated at each discrete time instant when any of the square-wave current excitation waveforms change levels. This ripple torque is caused by the combination of nonzero phase inductances and finite inverter DC voltage which prevents the phase current excitation waveforms from changing levels instantaneously.

The effects of torque ripple are particularly undesirable in some demanding motion control and machine tool applications. They lead to speed oscillations which cause deterioration in the performance. In addition, the torque ripple may excite resonances in the mechanical portion of the drive system, produce acoustic noise, and, in machine tool applications, leave visible patterns in high-precision machined surfaces. Given the importance of torque smoothness in many PMAC motor drive applications, a wide variety of techniques have been proposed for minimizing the generation of pulsating torque components. Broadly speaking. 
a

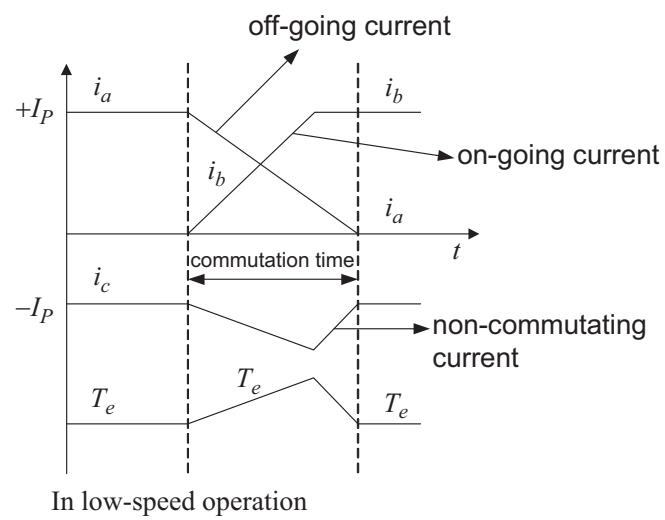

b

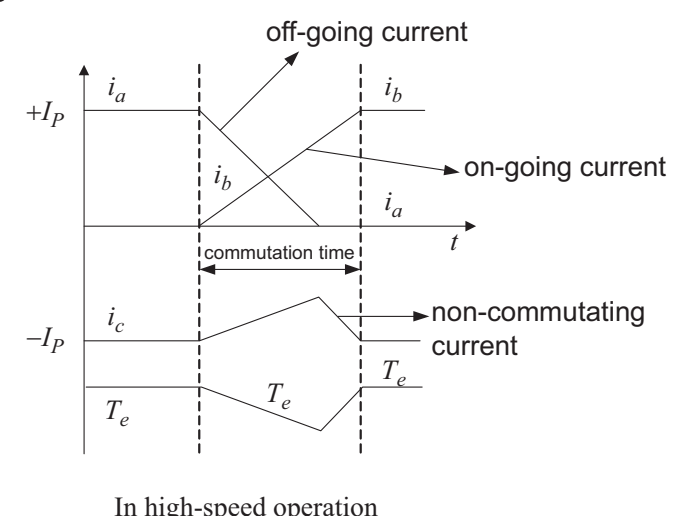

Fig. 1. Examples of commutation currents and torque.

these techniques fall into two major categories. The first class consists of techniques for adjusting the PMAC motor design in such a way to drive it toward ideal characteristics for achieving smooth torque production (Jahns \& Soong, 1996; Holtz \& Springob, 1996). Despite the wide range of motor design techniques that are available for reducing ripple torque components, there are many occasions when they are not either sufficient or appropriate to achieve the required minimization of these pulsating torques during motor operation. The second class of techniques for minimizing pulsating torque are based on active control schemes which modify the excitation to correct for any of the non-ideal characteristics of the motor, or its associated power inverter. One of the most popular approaches for actively controlling the ripple torques is to use programmed excitation waveforms for the phase currents (Berendesen, Champenois, \& Bolopion, 1993; Kim, Ahn, \& Hyun, 2001) to cancel the pulsating torque components. The individual phase current command waveforms are programmed as predetermined functions of the torque command and angular position to generate the desired average torque while canceling the pulsating torque components. The impact of the this approach on sinusoidal PMAC motor drives is relatively modest since the sinusoidal drive already requires that each of the phase currents be individually controlled as a function of torque command and rotor angle. In contrast, the impact of this scheme on the BLDC motor drive is far more significant. The rotor position sensors (often Hall sensors) which deliver the required commutation instant information must now be replaced by an encoder or a resolver to provide the necessary increased resolution in the rotor position feedback. Furthermore, the single current sensor located in the DC current link requires replacement by multiple current sensors to sense each of the individual phase currents. On the other hand, a significant variety of techniques for reducing commutation torque ripple have been proposed (Chung, Zhu, Lee, Lee, \& Cho, 2007; Kang, Kim, Mok, \& Cheo, 2001; Lee, Park, Yeo, \& Yoo, 1998; Liu, Zhu, \& Howe, 2007; Lu, Zhang, \& Qu, 2008; Murai, Kawase, Ohashi, Nagatake, \& Okuyama, 1989; Song \& Choy, 2004). Murai et al. (1989) introduced two different techniques for reducing the effects of commutation torque dips at elevated motor speeds. Since torque dips are caused by delays in building up current in the next on-going phase before the current in the off-going phase has decayed to zero, both techniques attempt to remedy this delay by giving the on-going phase a head start in its current build-up. The second torque dip attenuation technique introduces PWM excitation pulses during the intervals when each motor phase would normally be unexcited. This has the effect of allowing current to flow simultaneously in all three motor phases, allowing current to gradually build up in each sequential on-going motor phase during high-speed operation. While effective in reducing the speed ripple caused by commutation torque dips, both of these attenuation techniques suffer from the fact that they are open-loop in nature, requiring customized tuning for each set of motor parameters. Lu et al. (2008) introduced a new torque control method to attenuate torque ripple of BLDC motors with un-ideal back EMF waveforms. The action time of pulses are calculated regarding actual back EMF waveforms and the influence of finite dc bus supply voltage is considered in the commutation period. In the experiments two current sensors and one voltage sensor are used. And DSP TMS320F240 is used to make the torque feedback follow the torque reference.

Despite the expanding number of techniques that have been reported to date for minimizing pulsating torque production in BLDC motor drive, no practical and cost-effective solution has yet appeared for applications. In this paper, a compensation technique for reducing the commutation torque ripple in highperformance BLDC motor drives is proposed. In industrial sewing machine, the BLDC motor drives are widely used because of the cost reduction features, but the torque ripple leads to speed oscillations which cause deterioration in the performance and may excite resonances in the mechanical portion of the drive system, produce acoustic noise. With simple hardware implementation the proposed method is applied to the spindle motor drives for industrial sewing machines.

\section{Compensation for the commutation torque ripple}

The BLDC motor drive inverter uses a single current sensor in the DC link to regulate the current flowing through two motor phases in series, as shown in Fig. 2. This current regulation scheme works well except during the commutation intervals when the inverter link current is being shifted between adjacent motor phases. Current temporarily flows in all three motor phases simultaneously during these intervals until the current in the off-going phase decays to zero. The single current sensor cannot simultaneously regulate all three phase currents during these transition intervals, and this temporary loss of complete current control gives rise to commutation torque ripple during each current transfer interval. The commutation torque takes the form of torque spikes or dips which are generated at each discrete time instant when any of the square-wave current excitation waveforms change levels. Fig. 1(a) shows an example of the three phase current waveforms along with the instantaneous 


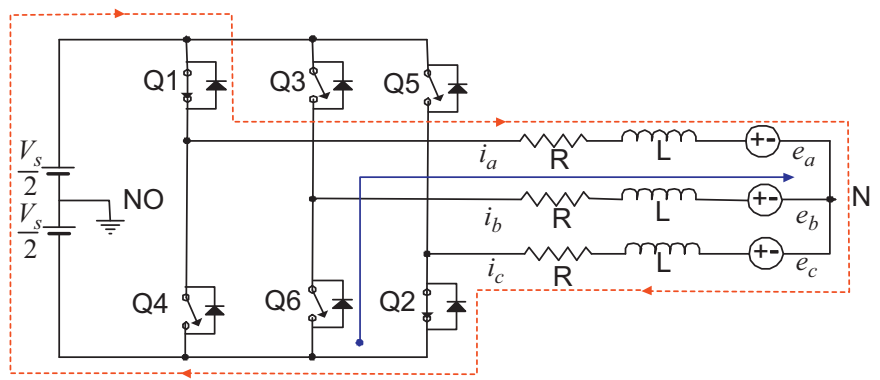

Fig. 2. Current paths and the equivalent circuit of BLDC motor drive (PWM ON).

torque waveform during low-speed operation when the phase current is being transferred from phase A (the off-going phase) to phase $B$ (the on-going phase). A current spike temporarily develops in the phase C. Fig. 1(b) shows a current dip developed in the phase $C$ during high-speed operation. The torque dips are caused by delays in building up current in the next on-going phase before the current in the off-going phase has decayed to zero. These current spikes and dips imposed on the phase $C$ can be minimized by using the method described in the proceeding section.

\subsection{Control strategy for torque ripple reduction in low-speed operation}

The analysis in this paper is based on the model shown in Fig. 2. The model represents the condition of current flowing in all three motor phases at commutation. At all other times only two phases are conducting. The representation of these conditions is accomplished by incorporating switching states into the model.

Fig. 2 shows the current paths and the equivalent circuit of BLDC motor drive when the switch Q1 and Q2 are turned on. In this case, the line-voltage equation is given by

$\frac{V_{s}}{2}=R i_{a}+L \frac{d i_{a}}{d t}+e_{a}+V_{N N O}$

$\frac{-V_{s}}{2}=R i_{b}+L \frac{d i_{b}}{d t}+e_{b}+V_{N N O}$

$\frac{-V_{s}}{2}=R i_{c}+L \frac{d i_{c}}{d t}+e_{c}+V_{N N O}$

$V_{N N O}=\frac{-V_{s}}{6}-\frac{e_{a}+e_{b}+e_{c}}{3}$

where $V_{s}$ is the inverter DC-link voltage, $R$ is the phase resistance, $L$ is the phase inductance, $e_{a}, e_{b}, e_{c}$, are the back electromotive forces (EMF) for phase A, B, C, $i_{a}, i_{b}, i_{c}$ are the currents for phase A, $\mathrm{B}, \mathrm{C}, V_{N N O}$ is the voltage between the neutral points of the inverter and the motor.

In unipolar PWM strategy, the switch Q1 is turned off while Q2 remains turned on, as shown in Fig. 3. In this case, the line-voltage equation is given by

$\frac{-V_{s}}{2}=R i_{a}+L \frac{d i_{a}}{d t}+e_{a}+V_{N N O}$

$\frac{-V_{s}}{2}=R i_{b}+L \frac{d i_{b}}{d t}+e_{b}+V_{N N O}$

$\frac{-V_{s}}{2}=R i_{c}+L \frac{d i_{c}}{d t}+e_{c}+V_{N N O}$

$V_{N N O}=\frac{-V_{s}}{2}-\frac{e_{a}+e_{b}+e_{c}}{3}$

$(4) \leftarrow$

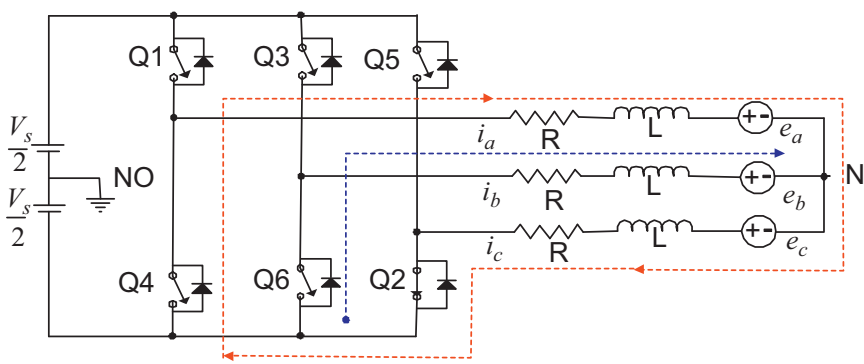

Fig. 3. Current paths and the equivalent circuit of BLDC motor drive (PWM OFF).

From Eqs. (2) and (4), the average voltage of the noncommutated phase during commutation interval is given by

$V_{m 2}=\frac{V_{s} d_{b}}{3}-\frac{4 e}{3}$

where $d_{b}$ is the PWM duty ratio in commutation period, and it is assumed that the back EMF $e_{a}$ and $e_{b}$ maintain the value of $e$ and $e_{c}$ holds at $-e$. And the voltage of the non-commutated phase during the non-commutation interval is given by

$V_{m 1}=\frac{V_{s} d_{a}}{2}-e$

where $d_{a}$ is the PWM duty ratio. Therefore, the average voltage of the off-going phase during the commutation interval is given by

$V_{m 3}=-\frac{V_{s} d_{b}}{3}+\frac{e}{3}$

Therefore, the voltage equation of the off-going phase during the commutation interval is given by

$R i+L \frac{d i}{d t}=\frac{-V_{s} d_{b}+e}{3}-e$

By solving the differential equation, the commutation time interval is given by

$t_{f}=-\frac{L}{R} \ln \left[\frac{V_{s} d_{b}+2 e}{3 R i_{p}+V_{s} d_{b}+2 e}\right]$

where $i_{p}$ is the initial value of the off-going phase current. The voltage equation of the on-going phase during the commutation interval is given by

$R i_{a}+L \frac{d i_{a}}{d t}=\frac{2 V_{s} d_{b}-2 e}{3}$

$(10) \leftarrow$

Thus, the commutation time interval at on-going phase $\left(t_{r}\right)$ is given by

$t_{r}=-\frac{L}{R} \ln \left[\frac{2 V_{s} d_{b}-2 e-3 R I_{p}}{2 V_{s} d_{b}-2 e}\right]$

To reduce the torque ripple during the commutation interval in low-speed operation, as shown in Fig. 1(a), a method to slow down the rising time of the on-going phase current can be a desirable technique to equalize the mismatched times of two commutated phase currents. Therefore, it is needed that the voltage of the non-commutated phase maintains constant during the non-commutation and commutation intervals for the phase current to maintain constant. From (5) and (6), the resultant duty ratio is given by

$d_{b}=\frac{3}{2} d_{a}+\frac{4 e}{V_{s}}$ 
By applying the duty ratio of Eq. (12) to the on-going phase instead of $d_{a}$ during the commutation interval, the rising time of the on-going phase current can be slowed down.

\subsection{Control strategy for torque ripple reduction in high-speed operation}

In high-speed operation, as shown in Fig. 1(b), the on-going phase current is delayed in building up before the current in the off-going phase has decayed to zero. From (9) and (11), the condition that the commutation time of off-going phase is equal to that of on-going phase is given by

$e=\frac{V_{s}-3 R I_{p}}{4}$

In speed region that exceeds (13), the two equations cannot be equal even if $d_{b}$ is equal to 1.0 (the maximum output of the inverter). Therefore, the other approach to compensate for the torque ripple is needed. A method to slow down the falling time of the off-going phase current becomes a desirable strategy to equalize the mismatched commutation times of the two commutated phase currents. To increase the off-going phase current, the switch Q3 is turned on during the commutation interval, as shown in Fig. 4. In this case, the line-voltage equation is given by

$\frac{V_{s}}{2}=R i_{a}+L \frac{d i_{a}}{d t}+e_{a}+V_{N N O}$

$\frac{V_{s}}{2}=R i_{b}+L \frac{d i_{b}}{d t}+e_{b}+V_{N N O}$

$\frac{-V_{s}}{2}=R i_{c}+L \frac{d i_{c}}{d t}+e_{c}+V_{N N O}$

$V_{N N O}=\frac{V_{s}}{6}-\frac{e_{a}+e_{b}+e_{c}}{3}$

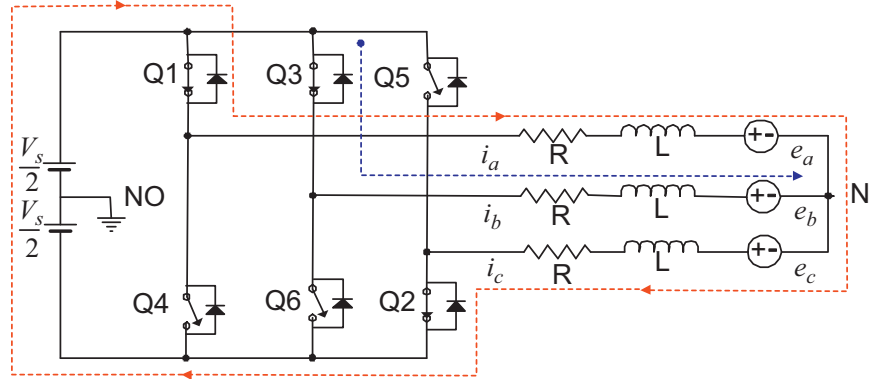

Fig. 4. Current paths and the equivalent circuit in high speed operation (PWM ON).

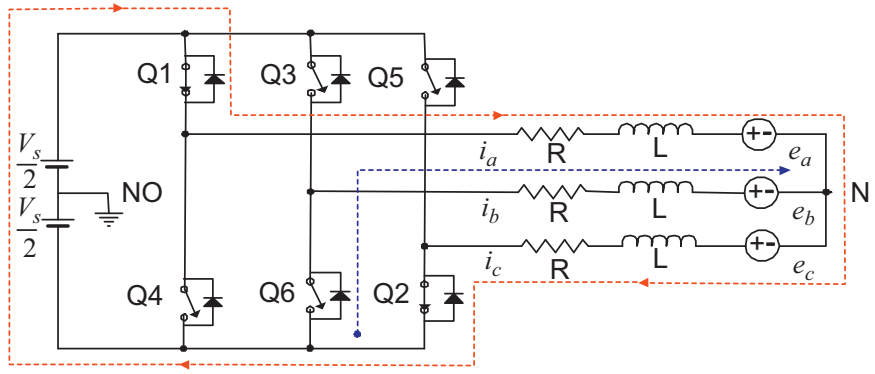

Fig. 5. Current paths and the equivalent circuit in high speed operation (PWM OFF).
As shown in Fig. 5, when the switch Q3 is turned off, the linevoltage equation is given by

$\frac{V_{s}}{2}=R i_{a}+L \frac{d i_{a}}{d t}+e_{a}+V_{N N O}$

$\frac{-V_{s}}{2}=R i_{b}+L \frac{d i_{b}}{d t}+e_{b}+V_{N N O}$

$\frac{-V_{s}}{2}=R i_{c}+L \frac{d i_{c}}{d t}+e_{c}+V_{N N O}$

$V_{N N O}=\frac{-V_{s}}{6}-\frac{e_{a}+e_{b}+e_{c}}{3}$

Therefore, the voltage equation of the off-going phase during the commutation interval is given by

$R i_{b}+L \frac{d i_{b}}{d t}=\frac{2 V_{s} d_{f}-V_{s}-2 e}{3}$

where $d_{f}$ is the PWM duty ratio in off-going phase during the commutation period. Similarly, the voltage equation of the ongoing phase during the commutation interval is given by

$R i_{a}+L \frac{d i_{a}}{d t}=\frac{-V_{s} d_{f}+2 V_{s}-2 e}{3}$

From (18) and (19), the commutation time intervals of offgoing phase and on-going phase are given by

$t_{f}=-\frac{L}{R} \ln \left[\frac{2 V_{s} d_{f}-V_{s}-2 e}{2 V_{s} d_{f}-V_{s}-2 e-3 R i_{p}}\right]$

$t_{r}=-\frac{L}{R} \ln \left[\frac{2 V_{s}-2 e-3 R i_{p}-V_{s} d_{f}}{2 V_{s}-2 e-V_{s} d_{f}}\right]$

The PWM duty ratio to satisfy the condition that (20) is equal to (21) is given by

$d_{f}=\frac{4 e+3 R I_{p}}{V_{s}}-1$

To compensate the torque ripple in high-speed region $\left(V_{s}-3 R I_{p}<4 e\right)$, the PWM duty ratio of the Eq. (22) is applied to the off-going phase during the commutation interval to equalize the mismatched times of two commutated phase currents.
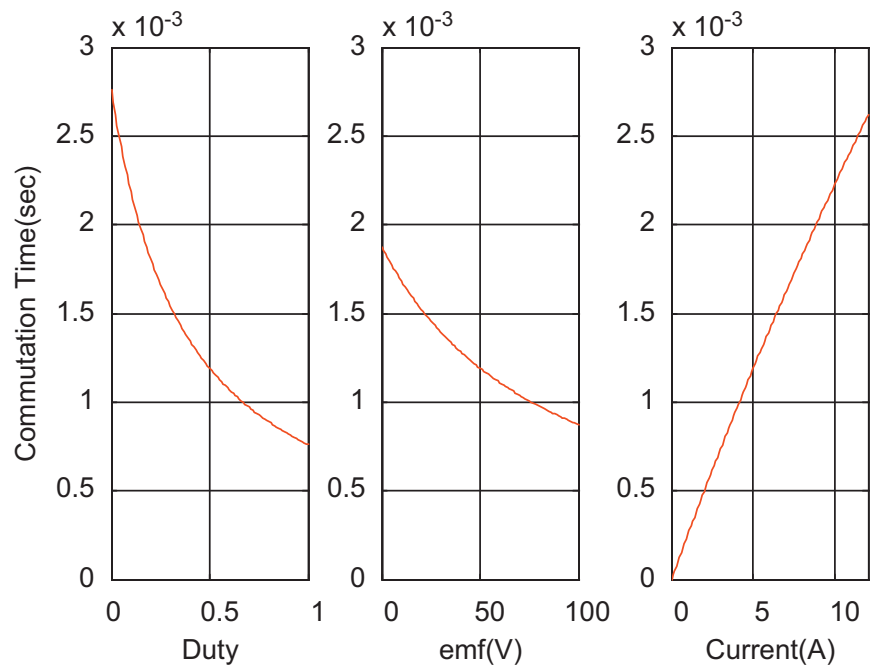

Fig. 6. Relation between the commutation time, duty, back EMF, and the initial current. 


\subsection{Implementation of control strategy for torque ripple reduction}

The compensation technique of the commutation torque ripple in low and high speed regions are described. However, the problem is how to calculate the commutation time intervals of (9) and (21) within the sampling period with the simple and cost-effective hardware such as one-chip microprocessors. In low-speed operation, the commutation time interval $\left(t_{f}\right)$ is the function of the back EMF $(e)$, the PWM duty ratio $\left(d_{b}\right)$, and the initial current $\left(i_{p}\right)$, as described in (9). Fig. 6 shows the relation between the commutation time and these motor parameters. Given the desired speed and the PWM duty ratio the commutation time is determined by using the two dimensional lookup table shown in Fig. 7, where the initial current is $12[\mathrm{~A}]$, the current limit of the given motor. Then, the final

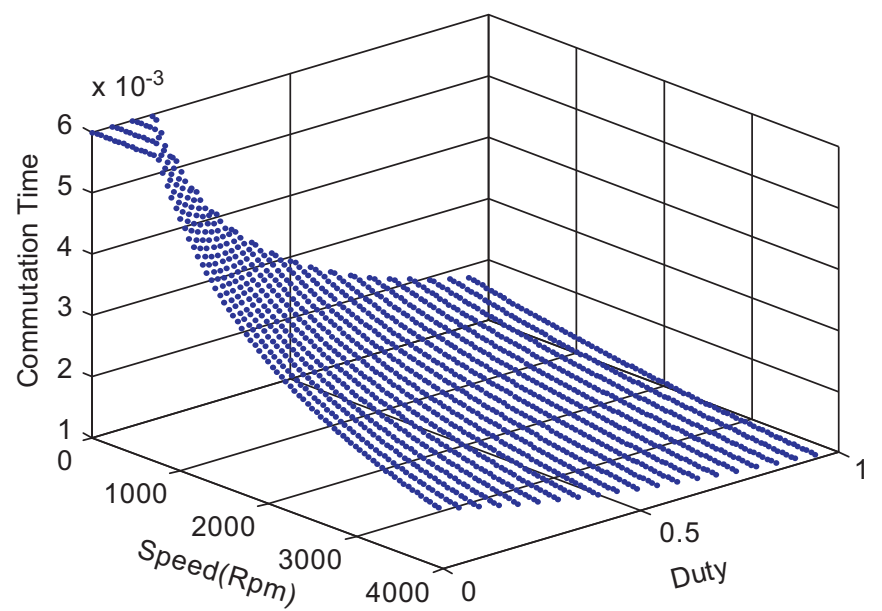

Fig. 7. The lookup table for the commutation time (in low-speed operation).

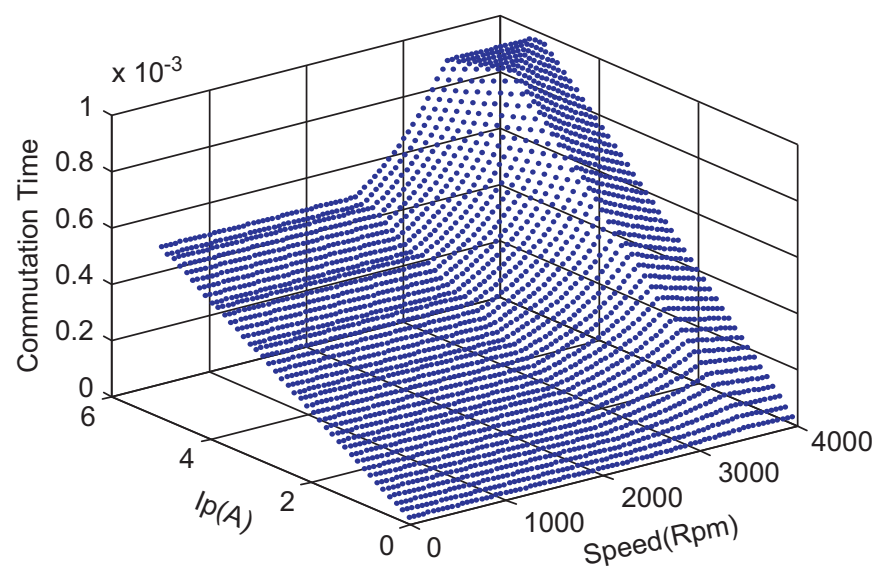

Fig. 8. The lookup table for the commutation time (in high-speed operation). commutation time is calculated from the linear relation between the commutation time and the initial current.

In high-speed operation, the commutation time is the function of the initial current $\left(I_{p}\right)$, the back $\operatorname{EMF}(e)$, and the duty ratio $\left(d_{f}\right)$, as described in (21). The PWM duty ratio of the off-going phase current is calculated by using (22). Then, the commutation time is determined from the two dimensional lookup table shown in Fig. 8.

For practical applications the proposed torque ripple reduction method can be combined with the speed controller for the BLDC motor, as shown in Fig. 9. For speed control the PI type controller is used. The PWM duty ratios of (12) and (22) are applied to the inverter.

\section{Experimental results}

To verify the feasibility of the propose method, experiments are carried out. Fig. 10 shows the experimental setup used. The parameters of the motor used in experiments are given in Table 1. For these experiments, a 16-bit microprocessor (16C80, Mitsubishi) is used for the controller. Additionally a CPLD (XC9572, Xilinx) is used to generate gate signals of the inverter and the commutation time signals. PWM1 and PWM2 are PWM duty ratios for torque ripple compensation in low and high speed operation, respectively.

Figs. 11 and 12 show the experimental results when the motor rotates at $50 \mathrm{rpm}$. The phase current is about $5.0 \mathrm{~A}$. The check signal displays the commutation interval generated by the method described in the previous section.

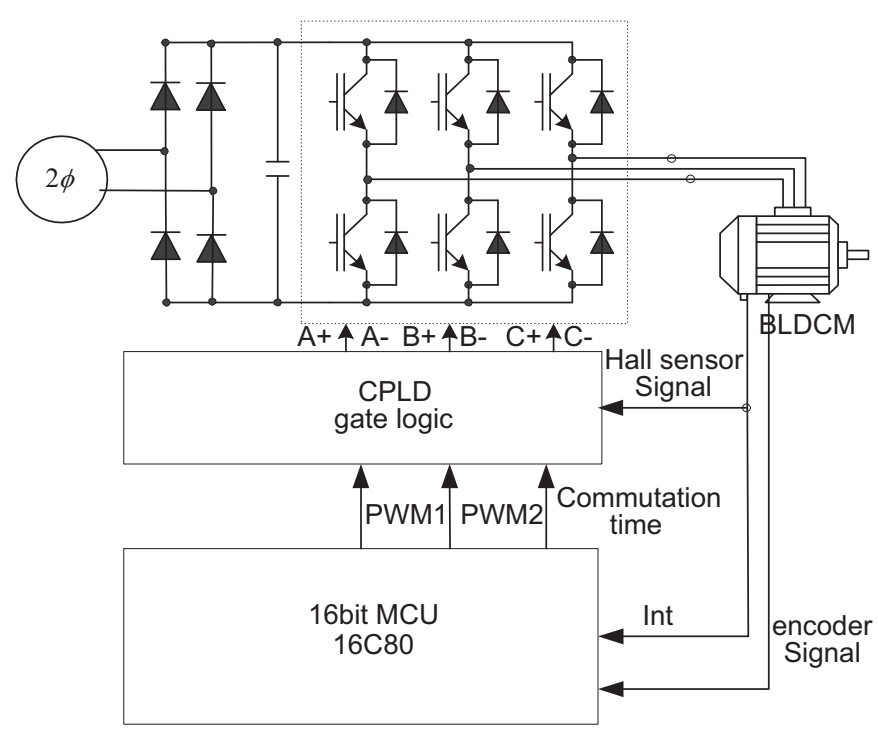

Fig. 10. Experimental setup.

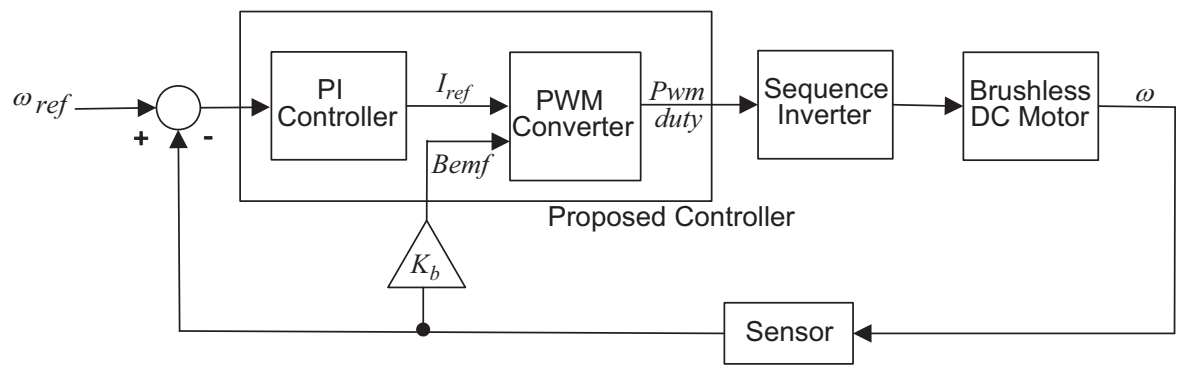

Fig. 9. The block diagram of the speed controller. 
Table 1

The motor parameters.

\begin{tabular}{ll}
\hline Rated power & $550 \mathrm{~W}$ \\
Rated speed & $3000 \mathrm{rpm}$ \\
Rated voltage & $170 \mathrm{~V}$ \\
Rated current & $3.2 \mathrm{~A}$ \\
Number of slots & 24 \\
Number of pole & 4 \\
Phase resistance $(R)$ & $2.47 \Omega$ \\
Phase inductance $(L)$ & $21.8 \mathrm{mH}$ \\
Torque constant $\left(K_{t}\right)$ & $0.29 \mathrm{Nm} / \mathrm{A}$ \\
Back EMF constant $\left(K_{e}\right)$ & $0.037 \mathrm{~V} / \mathrm{rpm}$ \\
\hline
\end{tabular}
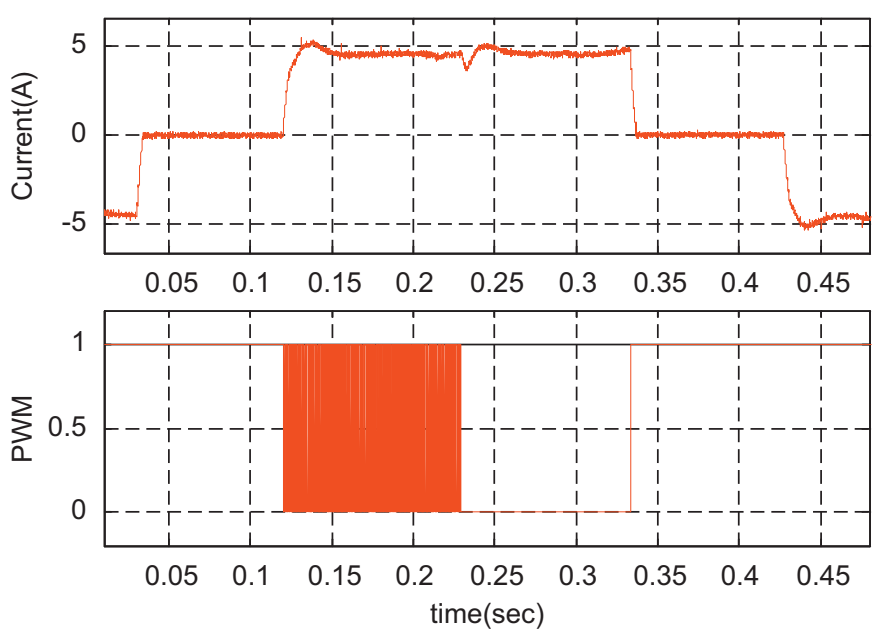

Fig. 11. Experimental result in low-speed range (without compensation).
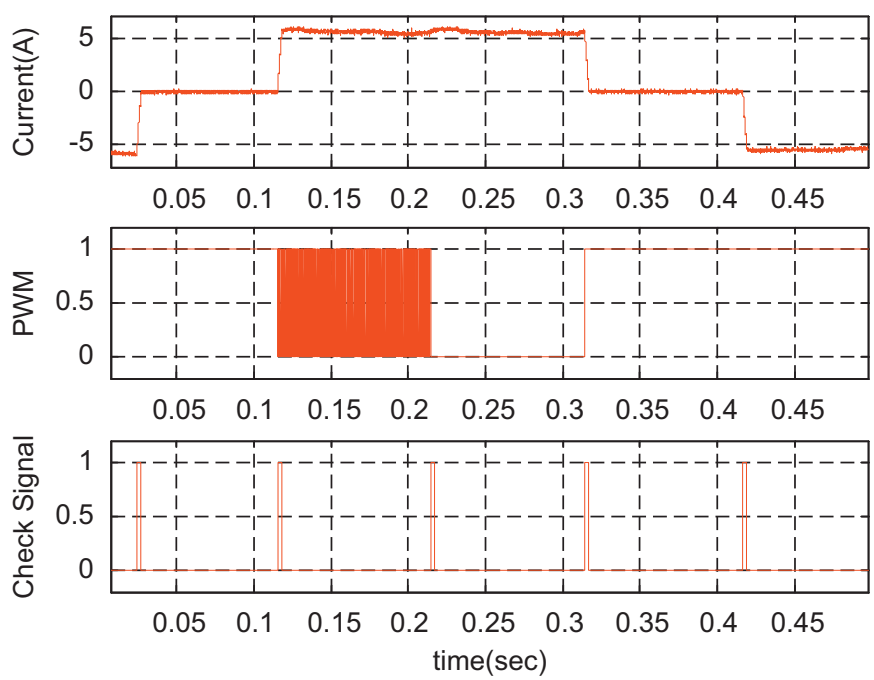

Fig. 12. Experimental result in low-speed range (with compensation).

Without compensation, as shown in Fig. 11, the phase current dip exists during the commutation interval. But, with the proposed compensation, as shown in Fig. 12, the current dip is eliminated during the commutation interval. Figs. 13, 14, and 15 show the experimental results when the motor rotates at $2800 \mathrm{rpm}$. Fig. 15 shows the magnified waveforms of Fig. 14. Without compensation, as shown in Fig. 13, the phase current ripple is significant during the commutation interval. With compensation, as shown in Fig. 14, the current ripple hardly appears. As shown in Fig. 15, the PWM pulses are applied to the
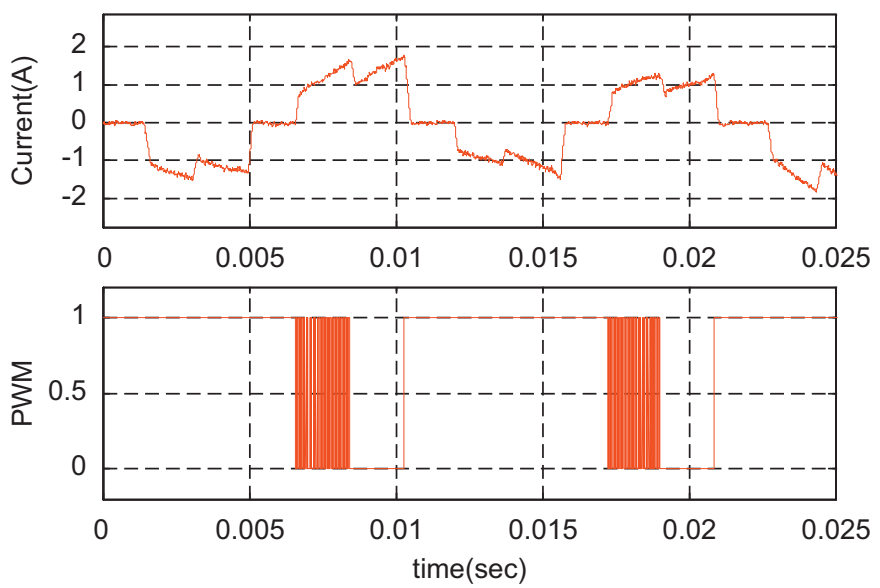

Fig. 13. Experimental result in the high-speed range (without compensation)


Fig. 14. Experimental result in the high-speed range (with compensation).
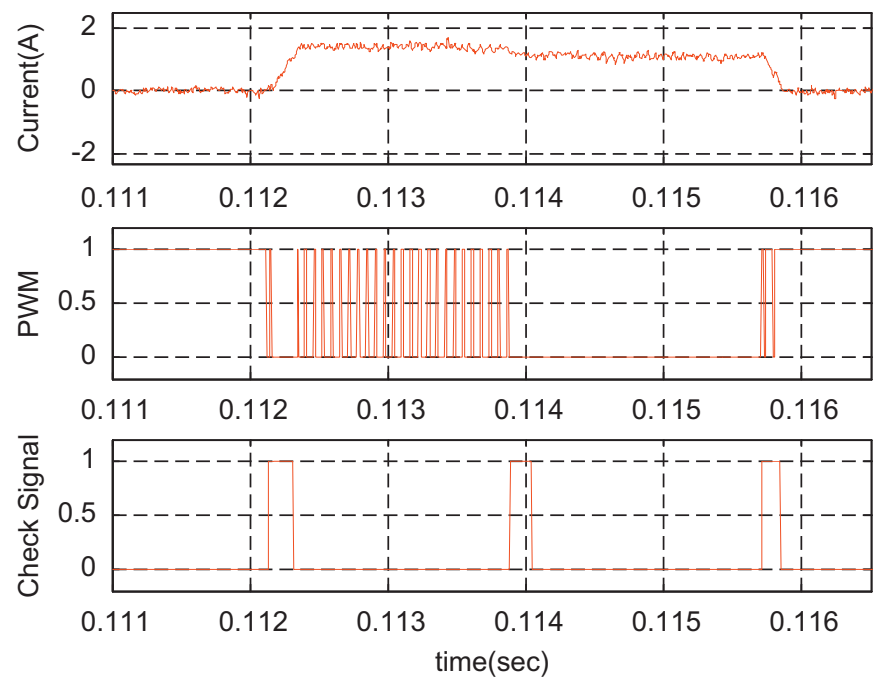

Fig. 15. Experimental result in the high-speed range (with compensation). 

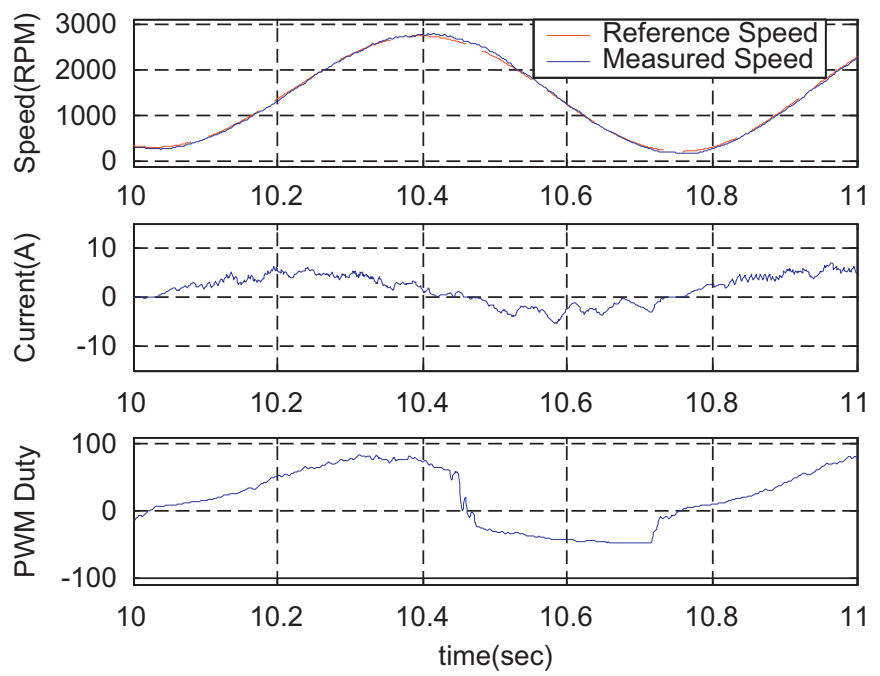

Fig. 16. Sine wave response for the proposed speed controller.

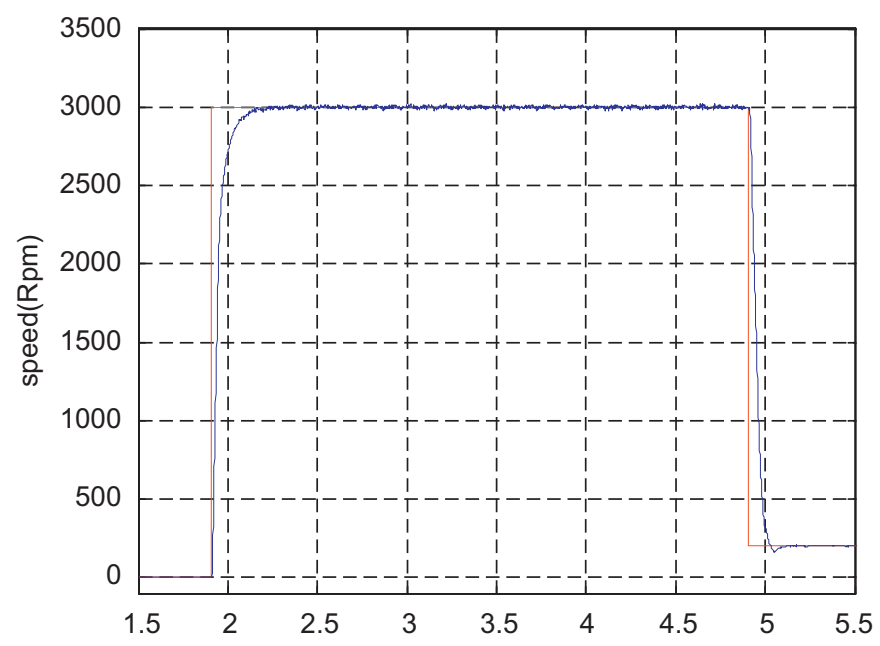

Fig. 17. Step response for the proposed speed controller.

off-going phase to slow down the falling time of the phase current. From these figures, it is noted that commutation torque ripples are effectively suppressed over the entire speed range with the proposed technique.

Figs. 16 and 17 show the experimental results of speed control combined with the proposed current ripple reduction method. In these figures, the resulting velocity profiles were very close to the reference signals. The step response had a rise time of $250 \mathrm{~ms}$. With the experimental results, the proposed method demonstrates the effectiveness for a control system using the BLDC motors that requires high speed and accuracy.

\section{Conclusion}

This paper has proposed a compensation technique for reducing the commutation torque ripple in high-performance BLDC motor drives. The idea is to equalize the mismatched times of two commutated phase currents during the commutation intervals. In low-speed operation, a method to slow down the rising time of the on-going phase current can be a desirable technique. In high-speed operation, a method to slow down the falling time of the off-going phase current becomes a desirable strategy. However, it is not easy to implement the proposed strategies by using cost-effective one-chip microprocessors because it is needed to calculate the commutation time intervals within the sampling period in low and high speed operation. Instead of calculating the commutation time intervals, two dimensional lookup tables that describe the relation of the commutation time interval and the motor parameters such as the back EMF and the initial motor current, are used. For the experiments, a 16-bit microprocessor was used for the controller. Additionally a CPLD (1600 gates) was used to generate gate signals of the inverter and the commutation time signals. To verify the feasibility of the propose method, it is applied to the spindle motor drive control for the industrial sewing machines. The effects of torque ripple are particularly undesirable in the industrial sewing machines. They lead to speed oscillations which cause deterioration in the performance. In addition, the torque ripple may excite resonances in the mechanical portion of the drive system, produce acoustic noise. With the experimental results, the proposed method demonstrates the effectiveness for a high-performance control system using the BLDC motors that requires high speed and accuracy.

\section{Acknowledgement}

This research was supported by Kangwon National University.

\section{References}

Berendesen, C., Champenois, G., \& Bolopion, A. (1993). Commutation strategies for brushless DC motor: influence on instant torque. IEEE Transactions on Power Electronics, 8(2), 231-236.

Carlson, R., Lajoie-Mazenc, M., \& Fagundes, J. C. S. (1992). Analysis of torque ripple due to phase commutation in brushless DC machines. IEEE Transactions on Industry Applications, 28(3), 632-638.

Chung, K., Zhu, Y., Lee, I., Lee, K., \& Cho, Y. (2007). Simulation of the reduction of force ripples of the permanent magnet linear synchronous motor. Journal of $E$. E. T, 2(2), 208-215.

Holtz, J., \& Springob, L. (1996). Identification and compensation of torque ripple in high-precision permanent magnet motor drives. IEEE Transactions on Industria Electronics, 43(2), 309-320.

Jahns, T. M., \& Soong, W. L. (1996). Pulsating torque minimization techniques for permanent magnet AC motor drives-a review. IEEE Transactions on Industria Electronics, 43(2), 321-330.

Kang, B., Kim, C., Mok, H., \& Cheo, G. (2001). Analysis of torque ripple in BLDC motor with commutation time. In: Proceedings of ISIE 2001 (pp. 1044-1048).

Kim, T., Ahn, S., \& Hyun, D. (2001). A new current control algorithm for torque ripple reduction of BLDC motors. In: Proceedings of IECON '01 (pp. 1521-1526).

Lee, K., Park, J., Yeo, H., \& Yoo, J. (1998). Current control algorithm to reduce torque ripple in brushless DC motors. In: Proceedings of ICPE'98 (pp. 380-385).

Liu, Y., Zhu, Z. Q., \& Howe, D. (2007). Commutation-torque-ripple minimization in direct-torque-controlled PM brushless DC drives. IEEE Transactions on Industry Applications, 43(4), 1012-1021.

Lu, H., Zhang, L., \& Qu, W. (2008). A new torque control method for torque ripple minimization of BLDC motors with un-ideal back EMF. IEEE Transactions on Power Electronics, 23(2), 950-958.

Murai, Y., Kawase, Y., Ohashi, K., Nagatake, K., \& Okuyama, K. (1989). Torque ripple improvement for brushless DC miniature motors. IEEE Transactions on Industry Applications, 25(3), 441-450.

Safi, S. K., Acarnley, P. P., \& Jack, A. G. (1995). Analysis and simulation of the highspeed torque performance of brushless DC motor drives. Proceeding of Electric Power Application, 142(3), 191-200.

Song, J., \& Choy, I. (2004). Commutation Torque reduction in brushless DC motor drives using a single DC current sensor. IEEE Transaction on Power Electronics, 19(2), 312-319. 